\title{
Trap crop diversity enhances crop yield
}

Joyce E. Parker ${ }^{\mathrm{a}, \mathrm{b}}$, David W. Crowder ${ }^{\mathrm{a}}$, Sanford D. Eigenbrode ${ }^{\mathrm{c}}$, William E. Snyder, ${ }^{\mathrm{a}, *}$

a'Department of Entomology, Washington State University, Pullman, WA 99164, United States

${ }^{\mathrm{b}}$ Current Address: Division of Community and Education, National Institute of Food and Agriculture, U.S. Department of Agriculture, 1400 Independence Ave., SW Mail Stop 2201, Washington, DC 20250-2201

'Department of Plant, Soil and Entomological Sciences, University of Idaho, Moscow, ID 83844, United States

*Corresponding author. Tel.: +1 509335 3724; fax: +1 509335 1009. E-mail address: wesnyder@wsu.edu (W. Snyder).

\section{ABSTRACT}

Diverse plantings provide many benefits for agroecosystem health. For example, "trap crops" that are highly attractive to pests can protect nearby, less attractive host plants. However, it is unclear whether increasing biodiversity of trap crops themselves might increase the effectiveness of this pest-management technique. We examined whether multi-species trap-crop plantings were more effective than any single species at protecting broccoli (Brassica oleracea var. italica) 
crops from the crucifer flea beetle, Phyllotreta cruciferae. Our trap crop plantings included between one and three plant species (Brassica juncea, Brassica napus, and/or Brassica rapa subsp. pekinensis), selected for their attractiveness to the beetles, while keeping total trap crop area constant. We found that only a diverse mix of all three trap-crops significantly improved yields of adjacent broccoli; indeed, the 3 -species polyculture provided protection that exceeded that of a monoculture of the most effective single trap crop species. Furthermore, the protective effect of diverse trap crop plantings extended across the broccoli beds. Treating trap crops with an insecticide provided no further benefits for pest control or broccoli yields. Despite clear benefits of trap-crop diversity on yields, the number of flea beetles did not differ in broccoli adjacent to diverse versus simple trap crops, or in the trap-crops themselves. This suggests that plant protection resulted from a change in pest behavior rather than abundance. Our study revealed that increasing biodiversity of trap-crop plantings might be an effective means to enhance the success of the approach in many systems.

Keywords:

Flea beetle

Broccoli

Chemical attraction

Complementarity

Crop diversification 


\section{Introduction}

Across many communities, ecosystem function improves as species richness increases (Hooper et al., 2005; Cardinale et al., 2006). This often occurs because increasing biodiversity increases the chance that species occupying complementary niches will co-occur (e.g., Finke and Snyder, 2008). Within agricultural fields, polycultures of two or more crop species often experience less damage from pests than when those same crops are planted as monocultures (Andow, 1991;

Letourneau et al., 2011). This may occur because polycultures complicate host-plant location by pests, and because polycultures provide the pests' natural enemies with a more diverse resource base that enhances enemy abundances and biological control (Root, 1973). At the scale of farm landscapes, crop rotation is a diversification scheme that forces pests to continuously relocate and re-colonize their preferred host plants from year to year (Tscharntke et al., 2005, 2007).

Trap cropping is a crop diversification scheme that often promotes pest suppression (Hokkanen, 1991; Shelton and Badenes-Perez, 2006; Cook et al., 2007). Trap cropping relies on pests having preferences for specific plant species, cultivars, or stages (Kennedy, 1965, 1978). Plantings of highly-preferred host plants can arrest arriving pests and "trap them", indirectly protecting a less-attractive (to the pest), but economically-valuable, nearby crop species (Hokkanen, 1991; Shelton and Badenes-Perez, 2006). For example, surrounding economicallyvaluable cucumber (Cucurbita sativa), butternut squash (C. moschata) or watermelon (Citrullus lanatus) crops with squash (C. maxima) varieties highly attractive to pestiferous beetles and bugs can intercept and arrest the herbivores and thus largely restrict pest damage to the trap crop (Radin and Drummond, 1994; Pair, 1997; Adler and Hazzard, 2009; Dogramaci et al., 2004). 
In most cases, trap-cropping schemes use a single attractive plant species to draw-in pests (but see Khan et al., 1997). However, there are several reasons to suspect that a diverse mix of trap species could provide more consistent, long-lasting attraction than a single species. First, herbivorous insects often locate and choose hosts using a blend of chemical cues, such that any single chemical constituent is not as attractive as a multi-compound blend (e.g., Nielsen et al., 1979; Webster et al., 2010). In such cases, different trap species that are emitters of different constituent compounds might combine to emit an overall more-attractive mixture. Likewise, the pairing of a trap species that is strongly chemically attractive (important in longer-distance host location) with a second trap species that provides visual/tactile cues (important for close-range host identification), might more-effectively draw in pests than either species alone (Eigenbrode et al., 2015). Furthermore, host plants often vary in their chemical profiles through time (e.g., Wallace and Eigenbrode, 2002; Lambdon et al., 2003), such that pairings of trap species with different attractiveness-phenologies might provide a long-lasting overall draw to the pest.

In a pair of field experiments, we examined whether multi-species trap-crop plantings were more effective than any single trap-crop species at drawing the crucifer flea beetle, Phyllotreta cruciferae, away from broccoli (Brassica oleracea var. italica) plantings. The chemical ecology of host location by this pest is well known (Feeny et al., 1970; Burgess and Weins, 1980; Lamb, 1983; Renwick, 2002; Shelton and Nault, 2004), which allowed us to select putative trap-crops that could attract/arrest the flea beetles. Our experiments lasted until broccoli harvest, providing a measure of impact on yield that is rarely considered in trap crop studies (but see Hokkanen, 1989). We next examined how far any protective effect extended into the protection target, and whether applications of an insecticide to the trap crop (e.g., Cavanagh et al., 2009, 2010) further enhanced crop yield. We replicated our treatments both west of the Cascade Mountains, where 
summers are relatively wet and cool, and east of the Cascade Mountains, where summers are typically hot and dry (USDA, 2012); we expected that flea beetle abundances and phenology might be quite different under these different environmental conditions. For similar reasons we continued our experiments across each of two separate growing seasons. In total then our study examined (1) whether increasing trap-crop biodiversity enhances pest control through interspecific complementarity among trap crop species; (2) whether the benefits of trap-cropping are seen primarily at the edges of the protection target's planting; (3) if the effectiveness of diverse trap-crops is increased by using insecticidal controls; and (4) whether any protective effect of trap crop biodiversity was consistent across two distinct climates, and across years.

\section{Methods}

\section{1. Natural history and chemical ecology of the crucifer flea beetle}

The crucifer flea beetle is an oligophagous pest of Brassica crops, accidentally introduced into North America from Eurasia in the 920s (Milliron, 1953; Westdal and Ramanow, 1972). The beetles possess several characteristics that make them good targets for control by trap cropping. First, adults emerge from overwintering sites located in field borders before moving into early-stage Brassica crops to feed (Lamb, 1983); this seasonal movement provides an opportunity to intercept flea beetles before they establish on Brassicas (Potting et al., 2005). Second, although the species specializes on Brassicaceae, its preference for settling and feeding differs strongly among hosts, providing opportunities for identifying trap crops (Altieri and Schmidt, 1986; Trdan et al., 2005). Third, host preferences of $P$. cruciferae are mediated through 
contact or long distance cues, including differences in surface wax characteristics that can arrest the insects (Bodnaryk, 1992) and plant volatiles to which they can be strongly attracted. These volatile cues include the hydrolysis products of glucosinolates, primarily allyl isothiocyanate (Feeny et al., 1970; Burgess and Weins, 1980; Renwick, 2002). Thus, plant species that release large quantities of these chemicals might be more attractive to beetles than crops that are the primary protection target. Variation in chemical profiles, and thus expected attractiveness to the flea beetle, suggests that overall greater attractiveness of a trap-crop planting might be achieved by a diverse trap crop planting that includes species with different chemical profiles, physical structures, and/or volatile profiles.

In a preliminary study, we compared the attractiveness to crucifer flea beetles of five putative trap-crop species: Barbarea vulgaris (yellow rocket), Brassica juncea (Pacific Gold mustard), Brassica napus (Dwarf Essex rape), Brassica oleracea var. acephala (Green Glaze collard) and Brassica rapa subsp. pekinensis (pac choi) (Parker, 2012). These species possess relatively high concentrations of glucosinolates and other plant-derived chemicals attractive to crucifer flea beetles (Root and Tahvanainen, 1969; Kinoshita et al., 1979; Shelton and Nault, 2004). They also differ in epicuticular wax characteristics, with all five species tending to possess reduced densities of wax crystals compared with B. oleracea var. italica, a trait associated with increased feeding by P. cruciferae (Bodnaryk, 1992). This study revealed that three of the plants that we examined, B. juncea, B. napus, and B, rapa subsp. pekinensis, were relatively attractive to crucifer flea beetles when the trap crops were planted in single-species monocultures (Parker, 2012); therefore, these three species were chosen for further investigation here.

\subsection{Experiment 1: trap-crop biodiversity and broccoli protection}


Our first field experiment compared the effectiveness of trap-crop monocultures, or mixtures of 2 or 3 species, of the putative highly-attractive plant species described earlier: B. juncea, B. napus, and B. rapa subsp. pekinensis. We used three metrics to delineate the effectiveness of each trap-crop composition: (1) biomass of nearby broccoli plantings at harvest; (2) abundances of flea beetles within the broccoli planting; and (3) abundances of flea beetles within the trap crop planting. Our methods to measure broccoli yields and flea beetle abundances in the protection target and trap crops was the same in both of the two field experiments we conducted, and are described following the description of Field Experiment 2 (Sections 2.4, 2.5).

This experiment included four treatments (with replicate numbers described below): (1) 0 trap-crop species, no trap crop present and the space otherwise occupied by a trap crop in the other treatments maintained as bare earth by plowing; (2) 1 trap-crop species, with each of the 3 trap crop species planted in separate monocultures as sub-treatments sharing a species richness of 1; (3) 2 trap-crop species, with each of the 3 different possible combinations of the three trap-crop species planted in different plots as sub-treatments; and (4) 3 trap-crop species. Trap crop diversity was manipulated using a substitutive design, where the total density of trap-crop plants was the same across simple and diverse trap-crop plantings; this was accomplished by planting each species at one-half its monoculture density in a two-species polyculture or onethird its monoculture density in a three-species polyculture. This design allowed us to examine whether diversity generally improved trap-crop effectiveness, or instead was unique to particular multi-species combinations (Snyder et al., 2006).

We repeated our experiment at two field sites: at Washington State University’s Mount Vernon Research and Extension Center, Mount Vernon, WA (west of the Cascade Mountains), 
and at the University of Idaho's Parker Plant Science Farm, Moscow, ID (east of the Cascade Mountains). At the west and east sites we constructed, respectively: 5 and 3 replicates of the notrap-crop controls; 8 and 5 replicates of each of the 3 trap crop species in monoculture, 8 and 2 replicates of each of the two-species polycultures (that is, each of the 3 possible unique combinations of 2 species was replicated either 8 or 2 times); and 13 and 5 replicates of the three-species polyculture. In total then, across the two geographic sites, our experiment included $8,39,30$, and 18 replicates of the $0,1,2$, and 3 species treatments, respectively, and 95 experimental units total across both sites and all treatments.

Trap-crop plantings consisted of two continuous rows of trap crop plants $5 \mathrm{~m}$ in length, flanking four rows of the target crop, with broccoli planted across $5 \mathrm{~m} \times 2.3 \mathrm{~m}$ and spaced 0.457 $\mathrm{m}$ within rows; broccoli rows were spaced $0.53 \mathrm{~m}$ apart. Trap crop plantings were either direct seeded or transplanted, depending on the crop. Seeds of B. juncea and B. napus were direct seeded at a rate of 5g/0.3 m in Moscow, ID on 10 May 2010 and in Mount Vernon, WA on 12 April 2010. Six-week-old B. rapa var. pekinensis were hand-transplanted on 6 May in Mount Vernon, WA and 13 May in Moscow, ID. After all trap plants were established in the field, sixweek-old broccoli seedlings were transplanted on 20 May in Mount Vernon and on 27 May in Moscow. We later quantified broccoli yield, and flea beetle abundances in the trap crop and the protection target, as described in sections 2.4 and 2.5 below.

\subsection{Experiment 2: Edge effects and the utility of spraying the trap-crop with insecticide}

The second experiment added two new objectives: (1) to determine whether any protective effect of the trap-crop was seen throughout the adjacent broccoli planting, or instead primarily 
near the crop edge, and (2) whether spraying the trap crop with a broad-acting insecticide would enhance the trap crop's ability to protect the broccoli. We next describe establishment of the experimental plantings for the second field experiment, followed by a description of broccoli and flea beetle sampling methods that were common to both experiments (Section 2.4).

This second experiment, which considered the same response variables as the first, included three treatments: (1) 0 trap-crop species (as in Experiment 1); (2) 3 trap-crop species unsprayed, the three-species trap-crop polyculture and no insecticide applied to the trap-crop; and (3) 3 trap-crop species sprayed, the three-species polyculture sprayed with a pyrethroid insecticide (Mustang Max® FMC, Philadelphia, Pennsylvania) at a rate of $219.2 \mathrm{~g} / \mathrm{ha}$ on 14 and 24 days after planting. We added a treatment where insecticide was applied to the trap crop because growers sometimes make these sprays to ensure that pests on the trap crop do not later return to the protection target if the attractiveness of the trap crop wanes (e.g., Cavanagh et al., 2009, 2010). Each treatment was replicated eight times at our west site (although space constraints limited us to 6 no-trap controls at that site) and twice at our east location. At both study sites, each replicate plot consisted of five rows of trap crop on one side nearest the perimeter of the first two rows of broccoli, with rows of both trap crop and broccoli being $5 \mathrm{~m}$ in length. Broccoli plants were planted in paired rows at three distances away from the trap crop: $0.59 \mathrm{~m}$ (near), $3.5 \mathrm{~m}$ (middle) and $7 \mathrm{~m}$ (far); these distances were determined based on plot size, which in turn was determined as a compromise between making each replicate as large as possible while at the same time having sufficient space in the fields available to establish multiple replicates of each treatment at each site. Broccoli plants were spaced $0.46 \mathrm{~m}$ apart within rows and both broccoli and trap crop rows were spaced $0.59 \mathrm{~m}$ apart between rows, with space between rows kept weed-free by hand weeding/hoeing. All plots were separated from one 
another by $3.5 \mathrm{~m}$ of bare ground. Trap crop plantings were either direct-seeded or transplanted, depending on the variety (described above). Seeds of mustard and rape were direct seeded at a rate of 5g/0.344 m in Moscow, ID on 1 June 2011 and in Mount Vernon, WA on 25 May 2011. Six-week-old B. rapa var. pekinensis were hand-transplanted 8 June 2011 in Mount Vernon, WA and 15 June 2011 in Moscow, ID. After all trap plants were established, six week-old broccoli seedlings were transplanted, on 22 June 2011 in Mount Vernon and on 29 June 2011 in Moscow.

\subsection{Measuring biomass of the protection target, broccoli}

We measured crop productivity in the two experiments in similar ways. Whole broccoli plants were harvested at 72 days (Experiment 1: 17 August at Mount Vernon, and 24 August in Moscow, 2010) and 78 days (Experiment 2: 8 September at Mount Vernon, and 15 September in Moscow, 2011) after broccoli transplanting. In the first experiment, 8 broccoli plants from the center of each plot were randomly selected using a random number generator to pick plants in each row, and harvested. In the second experiment, 3 broccoli plants were randomly harvested from each of the three distance-subplots $(0.59,3.5$, and $7 \mathrm{~m}$ from the trap crop) within each plot, for a total of 9 harvested plants per plot. In both experiments, harvested broccoli plants were pulled directly from the soil, shaken to remove excess soil, labeled, and placed into paper sacks. Plants were dried in an oven at $60^{\circ} \mathrm{C}$ for 7 days and dry weights were recorded for each sample.

\subsection{Crucifer flea beetle sampling in trap crops and on broccoli}


In both experiments, crucifer flea beetles were sampled, in both the trap crop and in the broccoli, using a D-vac suction sampler (Rincon Vitova, Ventura, California); we used suction sampling because preliminary work revealed that the jumping behavior that flea beetles deploy when disturbed made it too difficult to accurately count beetles using visual counts. In Experiment 1, crucifer flea beetles were sampled every two weeks over an 8-wk period, on 8 and 22 June and on 6 and 20 July in Mount Vernon (West), and on 1, 15 and 29 June and on 13 July in Moscow (East). In Experiment 2, once planting was completed, crucifer flea beetles were similarly sampled at two-week intervals between 31 June and 31 August.

In both experiments, to sample flea beetles (and other insects) from the trap crop, we first identified the middle of the trap crop plot, which was adjacent to three middle rows of broccoli. Starting on the first row of trap-crop plants, the D-vac collecting tube was held in place just above the canopy and shaken vigorously for 20 seconds in each row, for a total of 1 minute of suction sampling per plot. For the bare earth controls, the process was repeated except that the Dvac collecting tube was held ca. $4 \mathrm{~cm}$ above the ground surface and shaken for 20 seconds in each of three locations (corresponding to the three planted rows in the other treatments).

To sample flea beetles (and other insects) from the broccoli in Experiment 1, the D-vac collecting tube was positioned just above the canopy and shaken vigorously for 20 seconds near the center of each row of the plot. In Experiment 2 the procedure was similar except that separate samples were taken within each of the three sub-plots per plot, located 0.59, 3.5 and $7 \mathrm{~m}$ from the trap crop, respectively.

\subsection{Statistics}


For Experiment 1 we used linear regression to assess the effect of diversity ( 0 to 3 trap crop species) on the whole plant dry weight of harvested broccoli. Although our experiment was unbalanced, data did not violate the homogeneity of variance assumption (Brown-Forsythe test, $\left.F_{3,80}=2.11, P=0.11\right)$. We used generalized linear repeated-measures models with a negative binomial distribution (as a Poisson distribution was overdispersed) to analyze the impacts of trap crop diversity on flea beetle abundances in both trap crops and broccoli (separate analyses were conducted for the trap crops and broccoli) (Lindstrom and Bates, 1990; Vittinghoff et al., 2012). The repeated measures were the bi-weekly counts of flea beetle abundance at each plot over the course of the season. The repeated measures were modeled with an autoregressive error structure, because other error structures provided a poorer fit to the observed data based on information criteria (Bayesian Information Criteria).

For Experiment 2 we used ANCOVA to analyze the impacts of trap-crop treatment (control vs. sprayed vs. unsprayed) and distance from broccoli (distance was a continuous variable nested within trap-crop treatment) on broccoli whole plant dry weight. Although our experiment was unbalanced, data did not violate the homogeneity of variance assumption (Brown-Forsythe test, $\left.F_{2,81}=0.44, P=0.64\right)$. As with experiment 1 we used generalized linear repeated-measure models with a negative binomial distribution (as a Poisson distribution was overdispersed) to analyze the impacts of trop crop treatment on beetle abundances in the trap crops; to analyze impacts on flea beetle abundances in broccoli our model included both trap crop treatment and distance from broccoli (distance was a continuous variable nested within treatment) as explanatory variables. The repeated measures were the bi-weekly counts of flea beetle abundance at each plot over the course of the season. The repeated measures were modeled with an autoregressive error structure, because other error structures provided a poorer fit to the 
observed data as measured by information criteria (Akaike's Information Criteria and Bayesian Information Criteria). All data were analyzed using SAS (SAS Institute, 2010).

Diverse communities can out-perform those that are species-poor either because they bring together species that complement one another, or because they include particular species with strong impacts (Petchey, 2003; Hooper et al., 2005; Cardinale et al., 2006). Complementarity is most clearly indicated when the impact of diverse communities exceeds that of the single species that has greatest effect on the response of interest (in our case, broccoli yields) - what is known as 'overyielding' (Tilman et al., 2001). We quantified overyielding for yield data from the first experiment using the transgressive $\left(D_{\max }\right)$ value, which is commonly used to analyze results of biodiversity-ecosystem function experiments (Petchey, 2003). $D_{\max }$ quantifies the difference between the response of the single-most-impactful species in monoculture and that of the polyculture (Petchey, 2003). In our experiment, crop protection is considered to be improved when the overyielding values for broccoli whole plant dry weight is positive, indicating that broccoli plants were larger near diverse compared to simple trap crops (e.g., Ramirez and Snyder, 2009). When 95\% confidence intervals around the means did not overlap with zero, we considered this evidence for emergent biodiversity effects (e.g., Cardinale et al., 2006).

\section{Results}

\subsection{Broccoli yields}

In the first experiment, at both sites, yields were relatively low in the no-trap-crop control and 1-trap-crop-species treatments, while yields were highest in the 3-trap-crop-species 
treatment (diversity main effect: $t_{93}=3.06, P<0.003$; site $\times$ diversity interaction: $t_{93}=1.20, P=$ 0.23; Fig. 1a,b); yields in the 2-trap-crop-species treatment appeared to be relatively high at the east site, and relatively low at the west site (Fig. 1a,b). Overall, yields were significantly greater at the west (Mount Vernon, WA) than east (Moscow, ID) site $\left(t_{93}=-5.83, P<0.0001\right.$; Fig. 1a,b). Our overyielding calculations closely mirrored these results, demonstrating that the diverse, three-species mix of trap crops allowed for significantly greater broccoli yields than that of the single most effective trap-crop species in monoculture (Fig. A.1), which was B. rapa subsp. pekinensis at the east site and Brassica napus at the west site ( $\left.\mathrm{D}_{\max }\right)$.

In the second experiment we again saw the lowest broccoli yields in the no-trap control, and higher yields in broccoli planted adjacent to both treatments that included the 3-trap-species polyculture $\left(F_{2,72}=12.9, P<0.001 ;\right.$ Fig. $\left.1 \mathrm{c}, \mathrm{d}\right)$. However, yields were similar whether the diverse trap crop was sprayed or unsprayed (Fig. 1c,d) (post-hoc linear contrast: $F_{1,72}=1.55, P=0.22$ ). Yields were not significantly affected by the broccoli plants' distance from the trap crop $\left(F_{3,72}=\right.$ 1.77, $P=0.16$ ), at either site (site $\times$ distance [treatment] interaction: $F_{3,72}=1.32, P=0.27$ ).

\subsection{Crucifer flea beetle abundances in the trap crops}

For flea beetles within the trap crops themselves (or within the bare-earth controls) in the first experiment, a significant diversity $\times$ time $\times$ site interaction $\left(\chi^{2}=4.41, \mathrm{df}=1, P=0.036\right.$, Table 1a) appeared to reflect 2 factors (Fig. 2a, b): (1) lower flea beetle abundances in the notrap-control plots compared to the diverse polycultures, an effect that reached a higher magnitude at the east compared to the west site; and (2) a late season peak in flea beetle abundances seen in the east but not the west site. The effect of trap-crop diversity was more complex (Fig. 2a,b). A 
comparison among the diversity treatments (1,2,3 trap crop species), but with the no-trap control removed from the model to isolate any differences among the treatments that included trap crops, revealed a statistically-significant diversity $\times$ time $\times$ site interaction $\left(\chi^{2}=5.0, \mathrm{df}=1\right.$, $P=0.025$; Table 1 b) that appeared to be driven by consistently lowest flea beetle abundances in the 1-species treatment at the west site, but generally lowest flea beetle abundances in the 2species trap crop treatment east of the Cascades (Fig. 2a,b). Therefore, while flea beetle abundances were consistently low in the bare-earth controls compared to any of the trap crop treatments, within the trap crop itself species diversity yielded inconsistent effects across sites.

In the second experiment, we found a statistically-significant treatment $\times$ time interaction $\left(\chi^{2}\right.$ $=8.33, \mathrm{df}=2, P=0.016$ ), reflecting no treatment effects early in the season with later-season high flea beetle abundances in the un-sprayed 3-species trap crop treatment, intermediate flea beetle abundances in the sprayed 3-species trap crop treatment, and very low flea beetle abundances in the bare-ground control (Fig. 3). This pattern was consistent across the two geographic sites ( site $\times$ treatment interaction: $\chi^{2}=4.66, \mathrm{df}=2, P=0.090$; site main effect: $\chi^{2}=$ 0.75, df = 1, $P=0.39$; Fig. 3a, b).

\subsection{Crucifer flea beetle abundances in the protection target, broccoli}

Given the strong treatment effects for broccoli yield in the two experiments (Fig. 1), we expected to see trap-crop-diversity treatment effects on flea beetle abundances within the broccoli. However, there were no statistically significant treatment effects for crucifer flea beetle abundances on broccoli in experiment 1 (Table 2); a nearly-significant diversity effect $\left(\chi^{2}=3.77\right.$, df $=1, P=0.052$; Table 2 ) does not reflect any clear pattern seen through visual inspection of the 
data (Fig. 3). In the second experiment, for flea beetle abundances on broccoli we found that flea beetle densities in broccoli declined with increasing distance from the trap crop $\left(\chi^{2}=13.2\right.$, df $=$

3, $P=0.0042)$, and there was a statistically significant time $\times$ distance[treatment] interaction $\left(\chi^{2}\right.$ $=11.5, \mathrm{df}=3, P=0.0092)$ along with a statistically significant site effect $\left(\chi^{2}=9.11, \mathrm{df}=1, P=\right.$ 0.0025). These effects appear to reflect 4 factors: (1) increasing effectiveness of trap crops with greater spatial separation from the target broccoli crop; (2) dramatically higher flea beetle abundances on broccoli at the east compared to the west site; (3) at the west site only, higher flea beetle abundances at broccoli-plot edges early in the season; and (4) at the east site only, relatively low flea beetle abundances in plot centers when those plots were surrounded by the 3species trap crops, an effect not seen at this site in the absence of the trap crop (Fig. 4).

Therefore, while trap crop treatment altered flea beetle distributions within broccoli, the seasonal and spatial pattern of this effect dramatically differed between the two geographic sites.

\section{Discussion}

Trap cropping is a farm-diversification scheme that can benefit pest management (Hokkanen, 1991). While many studies have shown the accumulation of pest insects in trap crops (reviewed in Hokkanen, 1991; Shelton and Badenes-Perez, 2006; Cook et al., 2007; Eigenbrode et al., 2015), it has been less common to document increased yield for the crop being protected. We found that broccoli biomass increased 33\% or more (Fig. 1) when it was planted adjacent to 3species trap crops. These diverse trap crops were similarly effective at a site west of the Cascade Mountains, where summers feature relatively mild temperatures and relatively frequent rain, and one east of the Cascades, where typical summer conditions are relatively hot and dry. Results 
were similar in experiments conducted in two different years, strengthening the case that our trap-cropping approach could yield consistent crop-protection.

A limitation of our study was that, due to logistical constraints and the complexity of our experimental design, broccoli plots covered $<25 \mathrm{~m}^{2}$, much smaller than the typical scale of broccoli production on many farms. Trap crops often released chemical cues that herbivores might track over relatively long distances (Eigenbrode et al., 2015), and flea beetles are mobile insects that move seasonally between crop and non-crop vegetation (Lamb, 1983). This raises the possibility that, because of the limited spatial scale of our experiments, we were manipulating flea beetles as single populations at each of our field sites. This is a common problem with cropdiversification studies that can at times complicate extrapolating results to the scale of real working farms (Bommarco and Banks, 2003). Therefore, we support the suggestion that largerscale examinations of trap-cropping's possible benefits are still needed (Eigenbrode et al., 2015). Indeed, we found relatively strong reduction of flea beetles close to our trap crop plantings, with this effect weakening with increased distance from the trap (please see Results).

Trap-cropping schemes have generally paired one pest-attractive trap-crop species with one less-pest-attractive target crop species to be protected (Hokkanen, 1991; Shelton and BadenesPerez, 2006; Eigenbrode et al., 2015). In our study, none of the three trap crop species yielded any protection to broccoli when deployed alone (Fig. 1). Rather, consistent protection was provided only when all three trap crop species were deployed as a mixture (Fig. 1). This suggests that diversifying trap crop plantings might reveal effective multi-species mixtures even if the individual species are ineffective. Determining the mechanism underlying this diversity effect was beyond the scope of the work reported here, but we suggest a few possibilities for future investigation. For example, trap crop phytochemical blends might be complementary and when 
combined be more attractive than phytochemicals from any one species. For example, the primary glucosinolate in Pacific Gold mustard (B. juncea) is 2-propenyl glucosinolate, while the main aliphatic glucosinolates in green tissue and seed of rape (B. napus) are 2-hydroxy-3-butenyl glucosinolate, 3-butenyl glucosinolate, 4-pentenyl glucosinolate, and 2-hydroxy-4-pentenyl glucosinolate, in order of decreasing concentration (Davis, 1988). The combination of different glucosinolate profiles in our trap crops may have contributed to the success of the mixtures.

Trap crop mixtures might also be beneficial by providing an extended period of trapping activity though the season because phenologies are complementary, providing crucifer flea beetles with enhanced attractiveness to trap plants at different growth stages (Shelton and Badenes-Perez, 2006). For example, sequential planting of Indian mustard (B. juncea) improves cabbage protection from the diamondback moth by providing a highly-attractive food available throughout the season (Pawar and Lawande, 1995; Srinivasan and Krishna Moorthy, 1991). We saw that rape matured later in the season than mustard and pac choi (J.E. Parker, personal observation), such that crucifer flea beetles may have been continuously attracted to the highdiversity trap crop blend throughout the season, similar to the way sequential trap crop planting of a single species maintains an attractive trap throughout the growing season. Trapping can also be affected by attraction of the pest to the trap crop over distances, arrestment of the pest on contact with the trap crop, or a combination of these (Eigenbrode et al. 2015). A trap crop mixture could contain complementary attractive and arresting trap crops that combine to bring the pest into the trap crop, then retain it. Study of pest species behavioral responses to individual trap crops and to combinations could decipher this sort of behavioral complementarity.

In diversity manipulations such as ours, polycultures can outperform monocultures through at least two different mechanisms (Hooper et al., 2005). The first is interspecific complementarity, 
where species occupying distinctly-different niches combine to fill more total niche space than any single species (e.g., Finke and Snyder, 2009). Complementarity can only occur when multiple species are present, and so represents an emergent effect of biodiversity in the strictest sense (Loreau and Hector, 2001; Petchey, 2003). However, polycultures can also outperform monocultures simply because diverse communities are more likely to contain particularly effective single species. This mechanism, known as a "sampling effect", reflects the attributes of particular species rather than an outcome of greater biodiversity (Loreau and Hector, 2001). In our study the sampling effect appears unlikely to explain strong protection of broccoli only by diverse trap-crop polycultures, however. This is because the diverse trap-crop plantings promoted higher broccoli yields than the single most-protective trap species, B. rapa subsp. pekinensis at the east site and B. napus at the west site, when those species were planted alone ( $D_{\max }$; Fig. A.1). When the polyculture's effectiveness exceeds that of the most-efficacious single species, this provides particularly compelling evidence that species must be either complementing one another, or synergistically enhancing one another's effects, within polycultures (Petchey, 2003).

It is puzzling why the strong increase in broccoli yields when the protection target was planted alongside diverse trap crops (Fig. 1), occurred alongside an apparent overall lack of a corresponding reduction in flea beetle abundances within the broccoli plantings (Fig. 3, 4). One possibility, that diverse trap crops reduced damage from some pest species other than flea beetles, leading to increased yields, seems unlikely - the second-most-abundant pest in our broccoli plantings, the diamondback moth (Plutella xylostella), achieved numbers 65 -fold lower than flea beetles (Table A.1). One possible explanation is that the availability of a nearby, highly-attractive blend of trap crop species was impacting flea beetle feeding behavior more than 
flea beetle distribution. Indeed, crucifer flea beetles have been reported to exhibit continuous movement, and often display a wandering behavior even in the presence of suitable food (Kareiva, 1985). Despite the availability of high quality hosts, such as our high-diversity trap crop, crucifer flea beetle might exhibit trivial movements that frequently carry them onto the less acceptable target crop. This is supported by our observation that flea beetle abundances in broccoli decreased with increasing distance from the trap from. Moreover, we observed relatively intense feeding damage to our traps, but relatively infrequent feeding damage to our protection targets (J. E. Parker, personal observation). In addition, many studies have concluded that, when foraging within polycultures, herbivorous beetles emigrate more frequently and have shorter tenure times when they do arrest (Bach, 1984; Berguelson and Kareiva, 1987; Elmstron et al., 1988; Andow, 1991). Clearly, more research is needed on whether and how our diverse trap crops are altering flea beetle feeding behavior.

\section{Conclusions}

Modern agriculture practices, such as the widespread use of broad spectrum pesticides and the intensification of land use, have contributed to large-scale biodiversity losses that can negatively impact key ecosystem services in agricultural and other systems (Pimentel, 1961; Tilman et al., 2002; Tscharntke et al., 2005). This includes pest control (Altieri, 1999; Wilby and Thomas, 2002). Reversing the impacts of on-farm biodiversity loss remains a difficult challenge (Crowder et al., 2010). Trap cropping is one strategy for restoring functional biodiversity to farms. In our study, increasing species diversity in trap crops improved crop protection only when several trap-crop species were joined together (Fig. 1). Therefore, biodiversity at a 
somewhat finer scale, within the trap-crop planting itself, was necessary for the strategy to succeed. We suggest that species-diverse trap cropping schemes could be useful in other cropping systems. More generally, our findings emphasizes the significance of restoring the "right kind" of biodiversity to agroecosystems, that which brings together species that complement one another in ecologically-relevant ways (Poveda et al., 2008).

\section{Acknowledgements}

A special thanks to the field crew at the UI and WSU research farms who assisted with our fieldwork. This research was funded by grants from the USDA's Western Sustainable Agriculture Research and Extension Research and Education (grant SW08-102) and Graduate Fellowship (grant GW11-005) Programs.

\section{Appendix A. Supplementary data}

Supplementary data associated with this article can be found in the online version, at http://xx

\section{References}

Adler, L.S., Hazzard, R.V., 2009. Comparison of perimeter trap crop varieties: Effects on herbivory, pollination, and yield and butternut squash. Environmental Entomology 38, 207215. 
Altieri, M.A., 1999. The ecological role of biodiversity in agroecosystems. Agriculture, Ecosystems and Environment 74, 19-31.

Altieri, M.A., Schmidt, L.L. 1986. Populations trends and feeding preferences of flea beetles (Phyllotreta cruciferae Goeze) in collard wild mustard mixtures. Crop Protection 5, 170-175. Andow, D.A., 1991. Vegetational diversity and arthropod population response. Annual Review of Entomology 36, 561-586.

Bach, C.E., 1984. Effects of plant diversity and time of colonization on an herbivore-plant interaction. Oecologia, 44, 319-326.

Berguelson, M., Kareiva, P., 1987. Barriers to movement and the response of herbivores to alternative cropping patterns. Oecologia 71, 457-460.

Bodnaryk, R.P. 1992. Leaf epicuticular wax, an antixenotic factor in Brassicaceae that affects the rate and pattern of feeding in flea beetles, Phyllotreta cruciferae (Goeze). Canadian Journal of Plant Science 72, 1295-1303.

Bommarco, R., Banks, J.E., 2003. Scale as a modifier in vegetation diversity experiments: effects on herbivores and predators. Oikos 102, 440-448.

Burgess, L., Wiens, J.E., 1980. Dispensing allyl isothiocyanate as an attractant for trapping crucifer-feeding flea beetles. Canadian Entomologist 112, 93-97.

Cardinale, B.J., Srivastava, D.S., Duffy, J.E., Wright, J.Pl, Downing, A.L., Sankaran, M., Jouseau, C., 2006. Effects of biodiversity on the functioning of trophic groups and ecosystems. Nature 443, 989-992.

Cavanagh, A.F., Adler, L.S., Hazzard, R.V., 2010. Buttercup squash provides a marketable alternative to Blue Hubbard as a trap crop for control of striped cucumber beetles (Coleoptera: Chrysomelidae). Environmental Entomology 39, 1953-1960. 
Cavanagh, A.F., Hazzard, R., Adler, L.S. \& Boucher, J. 2009. Using trap crops for control of Acalymma vittatum (Coleoptera: Chrysomelidae) reduces insecticide use in butternut squash. Journal of Economic Entomology, 102, 1101-1107.

Cook, S.M., Khan, Z.R., Pickett, J.A., 2007. The use of push-pull strategies in integrated pest management. Annual Review of Entomology 52, 375-400.

Crowder, D.W., Northfield, T.D., Strand, M.R., Snyder, W.E., 2010. Organic agriculture promotes evenness and natural pest control. Nature 466, 109-112.

Davis, J.B., 1988. Winter rapeseed (Brassica napus L.) with differential levels of glucosinolates evaluated as a green manure crop to suppress Aphanomyces root rot of peas (Pisum sativum L.). MS thesis. University of Idaho, Moscow, Idaho.

Dogramaci, D., Shrefler, J.W., Roberts, B.W., Pair, S., Edelson, J.V., 2004. Comparison of management strategies for squash bugs (Hemiptera: Coreidae) in watermelon. Journal of Economic Entomology 97, 1999-2005.

Eigenbrode, S.D., Birch, A.N.E., Lindsey, S., Meadow, R., Snyder, W.E., 2015. Understanding push-pull strategies and their limitations: a mechanistic approach to improve stimulodeterrent pest management across multiple scales. Journal of Applied Ecology 53, 202-212.

Elmstrom, K.M., Andow, D.A., Barclay, W.W., 1988. Flea beetle movement in a broccoli monoculture and diculture. Environmental Entomology 17, 299-305.

Feeny, P., Paauwe, K.L., Demong, N.J., 1970. Flea beetles and mustard oils: host plant specificity of Phyllotreta cruciferae and P. striolata adults (Coleoptera: Chrysomelidae). Annals of the Entomological Society of America 63, 832-841.

Finke, D.L., Snyder, W.E., 2008. Niche partitioning increases resource exploitation by diverse communities. Science 321, 1488-1490. 
Gruber, M.Y., Xu, N. Grenkow, L. Li, X. Onyilagha, J. Soroka, J.J. Westcott, N.D., Hegedus, D.D., 2009. Responses of the crucifer flea beetle to Brassica volatiles in an olfactometer. Environmental Entomology 38, 1467-1479.

Hokkanen, H.M.T., 1991. Trap cropping in pest management. Annual Review of Entomology $36,119-138$.

Hokkanen , H.M.T., 1989. Biological and agrotechnical control of the rape blossom beetle Meligethes aeneus (Coleoptera, Nitidulidae). Acta Entomologica Fennica 53, 25-29.

Hooper, D.U., Chapin, F.S. III, Ewel, J.J., Hector, A., Inchausti, P., Lavorel, S., Lawton, J.H., Lodge, D.M., Loreau, M., Naeem, S., Schmid, B., Setala, H., Symstad, A.J., Vandermeer, J., Wardle, D.A., 2005. Effects of biodiversity on ecosystem function: a consensus of current knowledge. Ecological Monographs 75, 3-35.

Kennedy, J.S., 1965. Mechanisms of host plant selection. Annals of Applied Biology 56, 317322.

Kennedy, J, 1978. The concepts of olfactory 'arrestment' and 'attraction. Physiological Entomology 3, 91-98.

Khan, Z.R., Ampong Nyarko, K., Chiliswa, P., Hassanali, A., Kimani, S., Lwande, W., Overholt, W.A., Pickett, J.A., Smart, L.E., Wadhams, L.J., Woodcock, C.M., 1997. Intercropping increases parasitism of pests. Nature 388, 631-632.

Kinoshita, G.B., Svec, H.J., Harris, C.R., McEwan, F.L., 1979. Biology of the crucifer flea beetle, Phyllotreta cruciferae (Coleoptera: Chrysomelidae), in southwestern Ontario. Canadian Entomologist 111, 1395-1407.

Lamb, R.J., 1983. Phenology of flea beetle (Coleoptera: Chrysomelidae) flight in relation to their invasion of canola fields in Manitoba. Canadian Entomologist 115, 1493-1502. 
Lambdon, P.W., Hassall, M., Boar, R.R., Mithen, R., 2003. Asynchrony in the nitrogen and glucosinolate leaf-age profiles of Brassica: is this a defensive strategy against generalist herbivores? Agriculture, Ecosystems and Environment 97, 205-214.

Letourneau, D.K., Armbrecht, I., Rivera, B.S., Lerma, J.M., Carmona, E.J., Daza, M.C., Escobar, S., Galindo, V., Gutierrez, C., Lopez, S.D., Mejia, J.L., Rangel, A.M.A., Rangel, J.H., Rivera, L., Saavedra, C.A., Torres, A.M, Trujillo, A.R., 2011. Does plant diversity benefit ecosystems? A synthetic review. Ecological Applications 21, 9-21.

Lindstrom M.J., Bates, D.M, 1990. Nonlinear mixed effects models for repeated measures data. Biometrics 46, 673-687.

Loreau, M., Hector, A., 2001. Partitioning selection and complementarity in biodiversity experiments. Nature 412, 72-75.

Milliron, H.W., 1953. A European flea beetle injuring crucifers in North America. Journal of Economic Entomology 46, 179.

Pair, S.D., 1997. Evaluation of systemically treated squash trap plants and attracticidal baits for early-season control of striped and spotted cucumber beetles (Coleoptera: Chrysomelidae) and squash bug (Hemiptera: Coreidae) in cucurbit crops. Journal of Economic Entomology $90,1307-1314$.

Parker, J.E., 2012. Diversity by design: Exploring trap crops and companion plants to control Phyllotreta cruciferae, the crucifer flea beetle, in broccoli. Ph.D. Dissertation, Washington State University, Pullman, WA, USA.

Pawar, D.B., Lawande, K.E., 1995. Effects of mustard as a trap crop for diamondback moth on cabbage. Journal of Maharashtra Agricultural University 20, 185-186. 
Petchey, O.L., 2003. Integrating methods that investigate how complementarity influences ecosystem functioning. Oikos 101, 323-330.

Pimentel, D., 1961. Species diversity and insect population outbreaks. Annals of the Entomological Society of America 54, 76-86.

Potting, R.P.J., Perry, J.N., Powell, W., 2005. Insect behavioural ecology and other factors affecting the control efficacy of agroecosystem diversification strategies. Ecological Modeling 182, 199-216.

Poveda, K., Gomez, M.I., Martinez, E., 2008. Diversification practices: their effect on pest regulation and production. Revista Colombiana de Entomologia 34, 131-144.

Radin, A.M., Drummond, F.A., 1994. An evaluation of the potential for the use of trap cropping for control of striped cucumber beetle, Acalymma vittata (F) (Coleoptera, Chrysomelidae). Journal of Agricultural Entomology 11, 95-113.

Ramirez, R.A., Snyder, W.E., 2009. Scared Sick? Predator-pathogen facilitation enhances exploitation of a shared resource. Ecology 90, 2832-2839.

Renwick, J.A.A., 2002. The chemical world of crucivores: lures, treats and traps. Entomologia Experimentalis et Applicata 104, 35-42.

Root, R.B., 1973. Organization of plant-arthropod association in simple and diverse habitats: the fauna of collards. Ecological Monographs 43, 421-448.

Root, R.B., Tahvanainen, J.O., 1969. Role of winter cress, Barbarea vulgaris, as a temporal host in the seasonal development of the crucifer fauna. Annals of the Entomological Society of America 62, 852-855.

SAS Institute, 2010. SAS 9.0. SAS Institute, Cary, NC, USA. 
Shelton, A.M., Badenes-Perez, F.R., 2006. Concepts and applications of trap cropping in pest management. Annual Review of Entomology 51, 285-308.

Shelton, A.M., Nault, B.A., 2004. Dead-end trap cropping: a technique to improve management of the diamondback moth, Plutella xylostella (Lepdioptera: Plutellidae). Crop Protection 23, 497-503.

Snyder, W.E., Snyder, G.B., Finke, D.L., Straub, C.S., 2006. Predator biodiversity strengthens herbivore suppression. Ecology letters 9, 789-796.

Srinivasan, K., Krishna Moorthy, P.N., 1991. Indian mustard as a trap crop for management of major lepidopterous pests on cabbage. Tropical Pest Management 37, 26-32.

Tilman, D., Reich, P.B., Knops, J.M.H., Wedin, D., Mielke, T., Lehman, C.L., 2001. Diversity and productivity in a long-term grassland experiment. Science 294, 843-845.

Tillman, D., Cassman, K.G., Matson, P.A., Naylor, R., Polasky, S., 2002. Agricultural sustainability and intensive production practices. Nature 418, 671-677.

Trdan, S., Valič, N., Žnidarčič, D., Vidrih, M., Bergant, K., Zlatič, E., Milevoj, L., 2005. The role of Chinese cabbage as a trap crop for flea beetles (Coleoptera: Chrysomelidae) in production of white cabbage. Scientia Horticulturae 106, 12-24.

Tscharntke, T., Klein, A.M., Kruess, A., Steffan-Dewenter, I., Thies, C., 2005. Landscape perspectives on agricultural intensification and biodiversity-ecosystem service management. Ecology Letters 8, 857-874.

Tscharntke, T., Bommarco, R., Clough, Y., Crist, T.O., Kleijn, D., Rand, T.A., Tylianakis, J.M., van Nouhuys, S., Vidal, S., 2007. Conservation biological control and enemy diversity on a landscape scale. Biological Control 43, 294-309. 
Vittinghoff, E., Glidden, D.V., Shiboski, S.C., McCulloch, C.E. (eds), 2012. Regression Methods in Biostatistics: Linear, Logistic, Survival, and Repeated Measures Models. Springer-Verlag, New York, NY, 512 pp.

USDA, 2012. Plant Hardiness Zone Map. Agricultural Research Service, U.S. Department of Agriculture. Accessed from http://planthardiness.ars.usda.gov.

Wallace, S.K., Eigenbrode, S.D., 2002. Changes in the glucosinolate-myrosinase defense system in Brassica juncea cotyledons during seedling development. Journal of Chemical Ecology, 28, 243-256.

Webster, B., Bruce, T., Pickett J., Hardie, J., 2010. Volatiles functioning as host cues in a blend become nonhost cues when presented alone to the black bean aphid. Animal Behaviour 79, 451-457.

Westdal, P.H., Romanow, W., 1972. Observations on the biology of the flea beetle, Phyllotreta cruciferae (Coleoptera: Chrysomelidae). Manitoba Entomologist 6, 35-45.

Wilby, A., Thomas, M.B., 2002. Natural enemy diversity and pest control: patterns of pest emergence with agricultural intensification. Ecology Letters 5, 353-360. 
Table 1. Effects of trap crop diversity, site location, and time on crucifer flea beetle abundances in trap crops from the first experiment conducted in 2010. Results from the generalized linear mixed-models are shown with (A) all trap-crop treatments included and (B) only treatments with trap crops included (i.e., controls were removed from the analysis).

(A) All trap-crop treatments included

\begin{tabular}{lccc} 
Variable & $d f$ & $\chi^{2}$ & $P$ \\
Site & 1 & 4.37 & 0.037 \\
Diversity & 1 & 6.18 & 0.013 \\
Time & 1 & 7.25 & 0.0071 \\
Diversity $\times$ site & 1 & 4.67 & 0.031 \\
Time $\times$ site & 1 & 10.8 & 0.0010 \\
Diversity $\times$ time & 1 & 1.76 & 0.18 \\
Diversity $\times$ time $\times$ site & 1 & 4.41 & 0.036 \\
\hline
\end{tabular}

(B) Control treatments removed from analysis

$\begin{array}{lccc}\text { Variable } & d f & \chi^{2} & P \\ \text { Site } & 1 & 1.75 & 0.19 \\ \text { Diversity } & 1 & 3.74 & 0.053 \\ \text { Time } & 1 & 6.86 & 0.0088 \\ \text { Diversity } \times \text { site } & 1 & 2.72 & 0.099\end{array}$




\begin{tabular}{lccc} 
Time $\times$ site & 1 & 9.47 & 0.0021 \\
Diversity $\times$ time & 1 & 3.39 & 0.067 \\
Diversity $\times$ time $\times$ site & 1 & 5.00 & 0.025 \\
\hline
\end{tabular}


Table 2. Effects of trap crop diversity, site location, and time on crucifer flea beetle abundances in broccoli crops from the first experiment conducted in 2010. Results from the generalized linear mixed-models are shown.

\begin{tabular}{lccc}
\hline Variable & $d f$ & $\chi^{2}$ & $P$ \\
\hline Site & 1 & 0.01 & 0.94 \\
Diversity & 1 & 3.77 & 0.052 \\
Time & 1 & 1.30 & 2.55 \\
Diversity $\times$ site & 1 & 1.92 & 0.17 \\
Time $\times$ site & 1 & 2.57 & 0.11 \\
Diversity $\times$ time & 1 & 3.64 & 0.056 \\
Diversity $\times$ time $\times$ site & 1 & 0.11 & 0.75 \\
\hline
\end{tabular}




\section{Figure Captions}

Fig. 1. Broccoli yield harvested at the end of the season at the (a) west and (b) east sites in 2010, and at the (c) west and (d) east sites in 2011. Points represent mean ( \pm 1 SE) average broccoli whole plant dry weight by trap crop treatment.

Fig. 2. In the trap crop plots, abundances of crucifer flea beetles through time at the (a) west and (b) east sites in 2010, and at the (c) west and (d) east sites in 2011.

Fig. 3. In the broccoli plots for the 2010 experiment, crucifer flea beetles through time at the (a) west and (b) east sites.

Fig. 4. In the broccoli plots for the 2011 experiment, abundances of crucifer flea beetles through time in the Control treatment at the (a) west and (b) east sites; in the unsprayed polyculture treatment at the (c) west and (d) east sites; and in the insecticide-sprayed treatment at the (e) west and (f) east sites. 
Fig. 1.

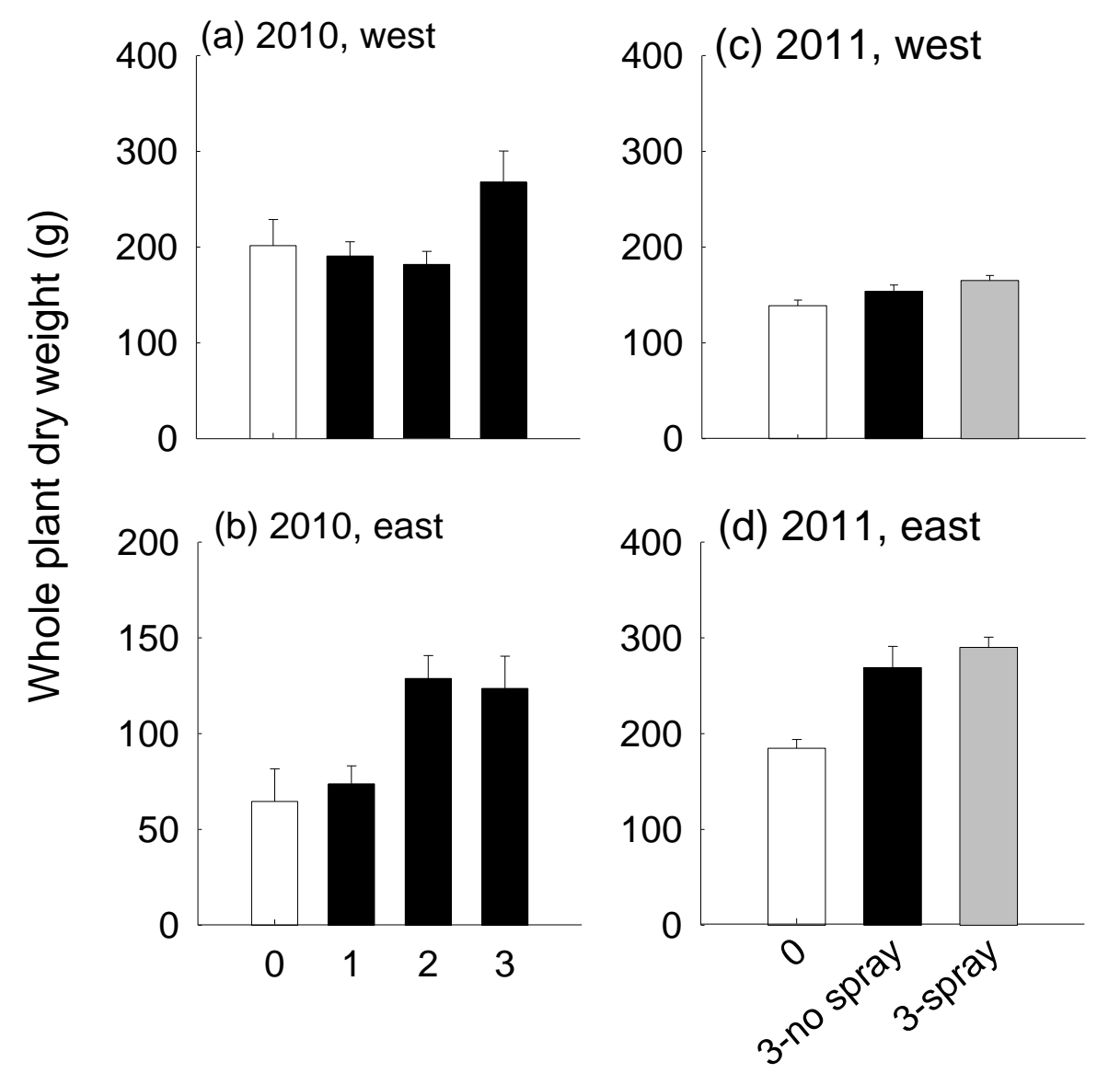

Trap crop species number

$\varpi$ control $\longrightarrow+$ trap crop $\rightleftharpoons+$ trap crop + spray 
Fig. 2
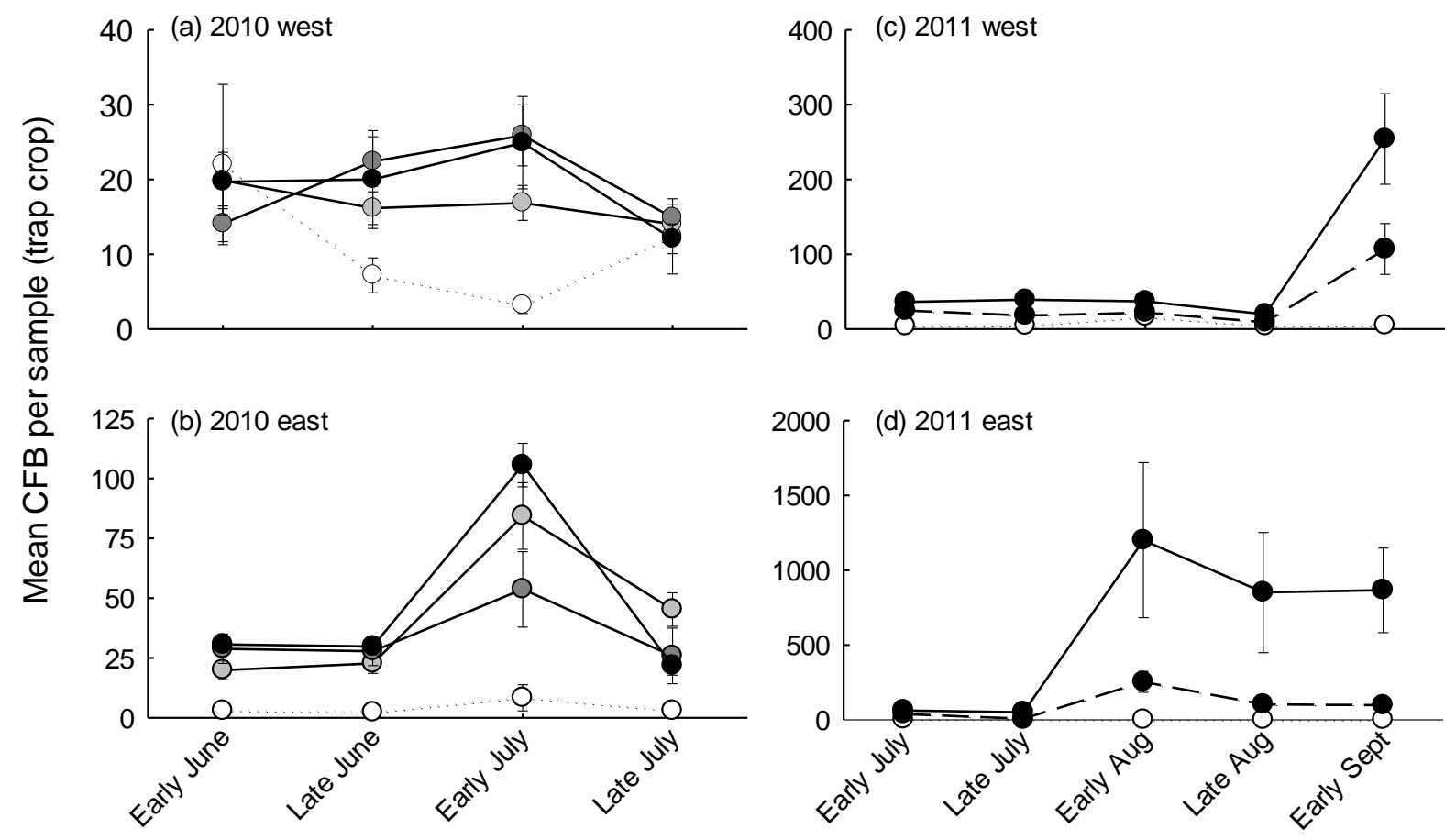

Sampling Period

\begin{tabular}{|c|c|c|c|c|c|}
\hline no trap & $-\frown 1 \mathrm{sp}$. & $-2 \mathrm{spp}$. & - 3 spp. & $-0-$ & $3+$ spray \\
\hline
\end{tabular}


Fig. 3.
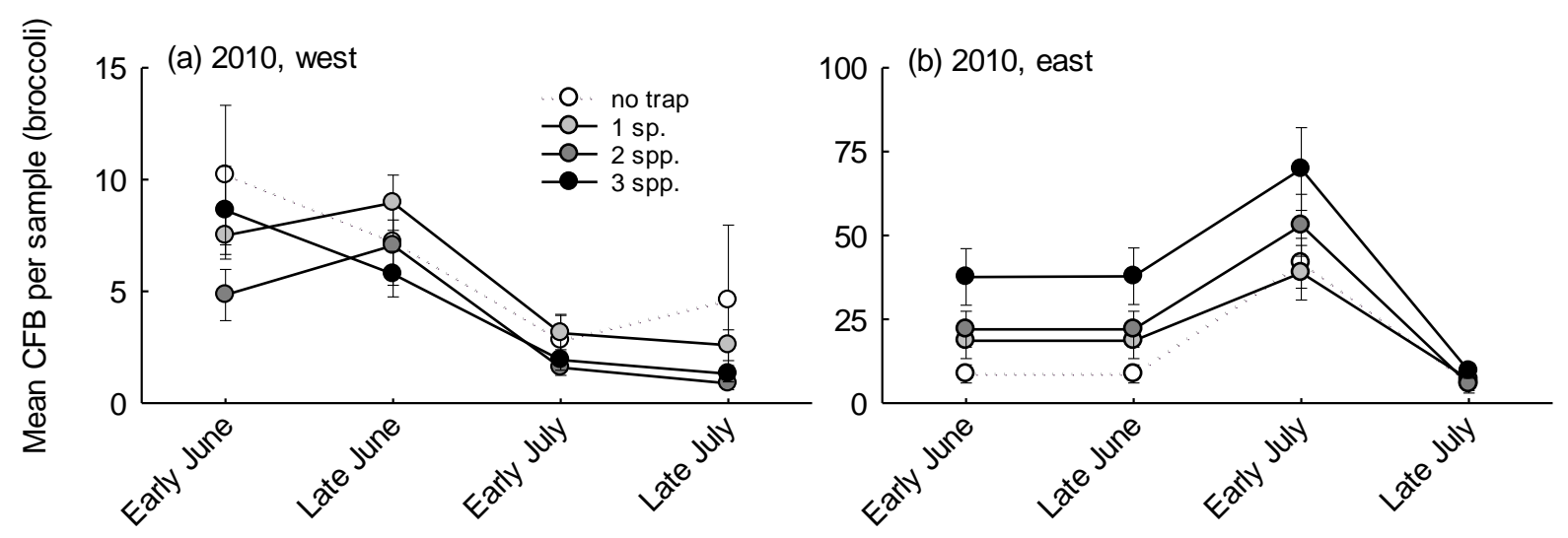

Sampling period 
Fig. 4
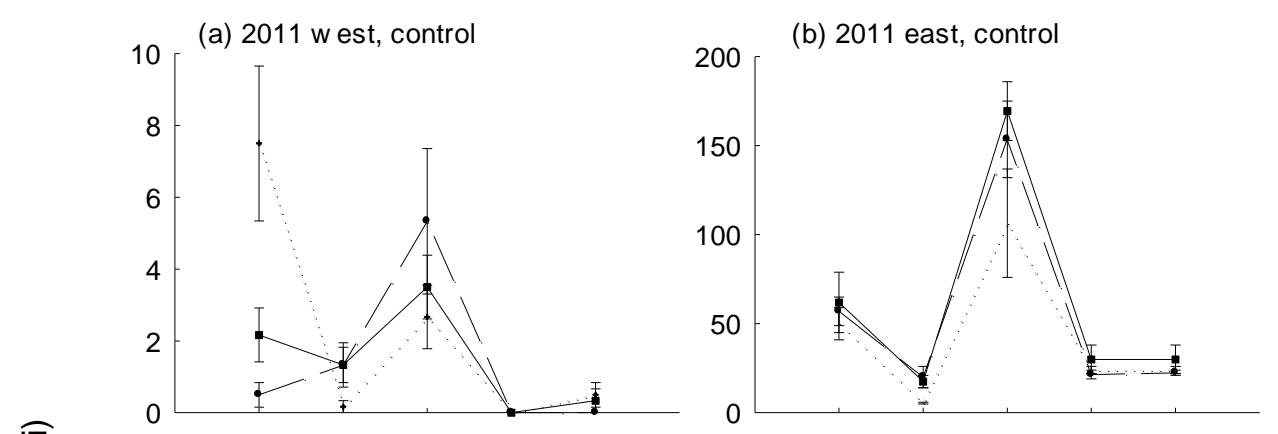

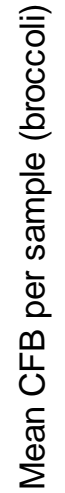
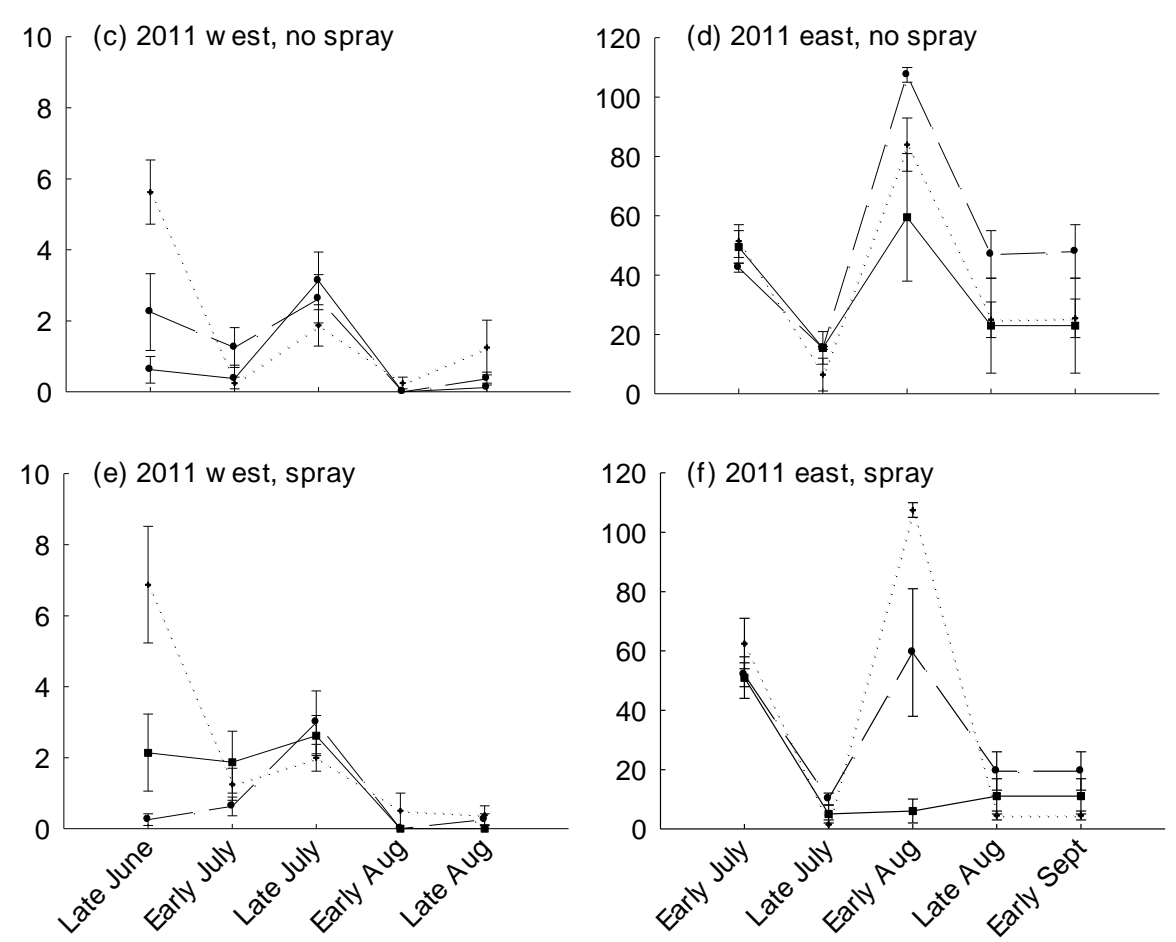

Sampling period

\begin{tabular}{|c|c|c|}
\hline ....... Near & $\longrightarrow$ Middle & 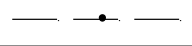 \\
\hline
\end{tabular}

